\title{
Introducing Taylor Series and Local Approximations using a Historical and Semiotic Approach
}

\author{
Rahim Kouki ${ }^{1}$, Barry J. Griffiths ${ }^{2 *}$ \\ ${ }^{1}$ Département de Mathématique et Informatique, Université de Tunis El Manar, Tunis 2092, TUNISIA \\ ${ }^{2}$ Department of Mathematics, University of Central Florida, Orlando, FL 32816-1364, USA \\ *CORRESPONDENCE: $\bigotimes$ barry.griffiths@ucf.edu
}

\begin{abstract}
In this article we present the results of a qualitative investigation into the teaching and learning of Taylor series and local approximations. In order to perform a comparative analysis, two investigations are conducted: the first is historical and epistemological, concerned with the pedagogical evolution of semantics, syntax and semiotics; the second is a contemporary institutional investigation, devoted to the results of a review of curricula, textbooks and course handouts in Tunisia and the United States.

Our results show that contemporary curricula emphasize the algebraic and analytic approaches to the theory but omit the graphical and numerical registers, which both played a large role in the historical development. We contend that by presenting a more historically accurate didactic approach, student learning can be enriched to give a deeper and more conceptually accurate understanding of the topic.
\end{abstract}

Keywords: Taylor series, local approximations, semantics, syntax, semiotics, instruction

\section{INTRODUCTION}

The research that we present in this article is part of the more general discussion of the articulation of syntax, semantics and semiotics in the teaching and learning of mathematics at the undergraduate level.

We are led to conduct this study involving Taylor series and local approximations by the fact that on the one hand they are fundamental to the understanding of mathematical analysis in both theoretical and practical terms in the fields of mathematics, engineering, and physics, but on the other hand, most of the research conducted with regard to these objects has not explicitly discussed teaching and learning, even when referring to their importance.

This is not to say that the present study is totally independent of those already conducted. Artigue (2004) focused on the difficulty of transitioning from algebraic analysis to formal analysis, as did Bloch and Gibel (2011), who showed the existence of a gap due to a "conceptual leap" in the transition from high school to university, highlighting the complexity in teaching new concepts at the beginning of an undergraduate program, for example the construction of the real numbers, solving differential equations, linear approximations, etc.

Others, like Durand-Guerrier (2008), Durand-Guerrier and Arsac (2005), and Kouki et al. (2016) have shown the relevance of considering semiotic, semantic and syntactic analysis in the teaching and learning of objects in real analysis at the end of high school and the beginning of degree programs.

Article History: Received 8 May $2019 \bullet$ Revised 9 September $2019 \bullet$ Accepted 6 November 2019

(C) 2020 by the authors; licensee Modestum Ltd., UK. Open Access terms of the Creative Commons Attribution 4.0 International License (http://creativecommons.org/licenses/by/4.0/) apply. The license permits unrestricted use, distribution, and reproduction in any medium, on the condition that users give exact credit to the original author(s) and the source, provide a link to the Creative Commons license, and indicate if they made any changes. 
In this paper, we posit that the inclusion of semantic and syntactic dimensions with regard to Taylor series should be better clarified both in the internal and external transposition ${ }^{1}$ process (Chevallard, 1992). After a brief clarification of the terms from semiotics that permeate this paper, we present the development of the theory of Taylor series through a historical and epistemological analysis of how different techniques have contributed to the advancement of our understanding of this object. Later, we contrast this with the main results of an analysis of the curriculum in Tunisia and the United States involving Taylor series, with a focus on how the contemporary pedagogical and semiotic approaches compare with the earlier historical analysis.

\section{SYNTAX, SEMANTICS AND SEMIOTICS}

The language of mathematical logic is defined by a syntax that provides a system governed by symbols and rules that combine to make formulas, along with associated semantics that allow us to give a proper interpretation to the symbols and the formulas constructed using them. Syntax provides an alphabet of symbols which are by themselves meaningless but can be combined and transformed into statements according to established rules, which can then be judged as being valid or invalid. We also use the term syntactic in a broader sense to encompass the theory of formal demonstration, as opposed to semantics, which takes into account the interpretations.

Semiotics in this instance represents the study of mathematical symbols, with an emphasis on how they are used and interpreted. Once a language has been formalized, semantics then study the possible interpretations of the symbols used as well as the relationships between the various interpretations of the formulas.

\section{HISTORICAL AND EPISTEMOLOGICAL STUDY OF TAYLOR SERIES}

The problems of infinitesimal calculus have been studied since antiquity. In particular, the Greeks considered infinitesimal calculus using geometric techniques, such as squaring or cubature, developed by Archimedes, and the tangents to conics, which were thoroughly investigated by Apollonius.

In this section, we will focus our attention on the period between the early seventeenth and late nineteenth centuries, during which many important moments occurred with regard to the development of infinitesimal calculus and local approximations. We will present and interpret the work of mathematicians from that era, which witnessed the spread of calculus among European mathematicians who now had the resources and formal algebraic knowledge to solve new geometric problems that were more complex than those considered by the Greeks.

We will consider the techniques developed by the different mathematicians from a semantic, syntactic and semiotic perspective to provide educational insight into the different techniques, following an approach developed and used by Kouki (2018).

In the seventeenth century, velocity problems, quadratures, tangents, maxima and minima were the leading focus of differentiation problems, with a geometric approach being dominant among mathematicians and physicists. Indeed, Bourbaki (1994), writes that:

"These quadratures are the subject of much work, by Grégoire de Saint-Vincent, Huygens, Wallis, Gregory; the first believes he has succeeded in the quadrature of the circle, the last believes he has proved the transcendence of pi; with the ones and the others procedures of indefinite approximation are developed for the circular and logarithmic functions, the ones with a theoretical tendency, the others oriented towards numerical calculation, which is going to end soon, with Newton, Mercator, J .Gregory, then Leibniz, with general methods of expansion in series" (p. 181).

While ancient in origin, the problem of tangents was not studied in detail until the work of Fermat, Torricelli and Roberval. Stedall (2008) wrote that:

"By 1636, both Roberval and Fermat knew that the value of $\sum_{x=0}^{X} x^{n}$ is approximately $\frac{X^{n}}{n+1}$ when $n$ is a positive number and $x$ is taken at sufficiently small intervals between 0 and $X$. Both used this relationship to find the quadrature of curves of the form $=x^{n}$. Fermat corresponded with Torricelli on the subject in 1644" (p. 79).

\footnotetext{
${ }^{1}$ Didactic transposition involves deconstructing scientific theory and adapting it to a more teachable form. External didactic transposition is regulated by forces outside of the classroom. Internal didactic transposition consists of teachers adapting the curriculum to their classroom teaching.
} 
Throughout this period the work of Fermat, Descartes, Wallis, Newton and Leibniz was mainly based on approximation, but in their studies of the "tangent problem" the first two terms of the Taylor expansion were developed. This was expanded upon by Barrow, of whom it is written by Dahan-Dalmédico and Peiffer (2010):

"Barrow was the first to clearly recognize that the problem of tangents was the inverse of the problem of quadratures, and vice versa. He recognized the generality and importance of the connection that today is the fundamental theorem of differential and integral calculus" (p. 203).

In the early seventeenth century, the Taylor series came to be viewed as a way of developing infinite series in calculus. Its genesis is due to its ability to solve physical and mathematical problems.

Firstly, the resolution of the tangent problem in the early seventeenth century alluded back to the original context of the tangent line by determining its equation using a dynamic method developed by Torricelli and Roberval. On the one hand it was based on the speed of a moving object at a point and on the other by a geometric method (or the determination of the first terms of Taylor expansion) used by Fermat, Descartes and Barrow.

"Torricelli and Roberval considered the curves created by the composition of two movements whose velocities are known. The resultant velocity will be the diagonal of the parallelogram of the velocities of the two movements which create the curve. The line having the direction of the diagonal will be tangent to the curve at the point $P$ (see Figure 1). This dynamic method allowed determination of tangents to many curves, but the definition of tangent used there rested on physical concepts and was not applicable to all curves" (Dahan-Delmédico \& Peiffer, 2010, p. 198-199).

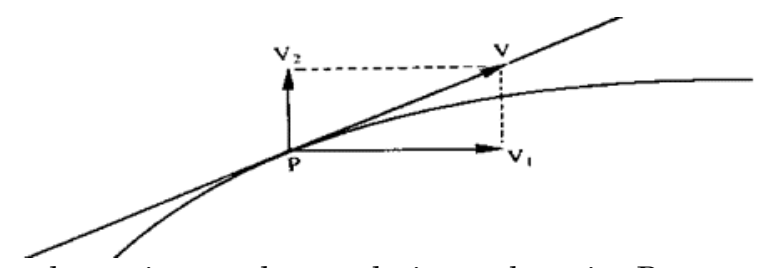

Figure 1. Dynamic method to determine resultant velocity at the point $\mathrm{P}$

Hence, we can say in this instance that the approach developed to find the algebraic equation of the tangent line uses a semantic technique in the graphical register to syntactically model the algebraic equation of the tangent.

Later in the seventeenth century, Taylor series were considered via developments made in infinite series (in particular those for sine, cosine, tangent and $\ln (1+x)$ ), which were performed using geometric techniques by Leibniz, building on foundations developed by Nicolas Mercator, which were published in his Logarithmotechnia in 1668. They articulated the semantic and syntactic dimensions of the algebraic framework utilizing a graphical register. Stedall (2008) wrote that:

"Mercator's method was based on the work of Wallis in the Arithmetica infinitorum of 1656. Wallis, like Fermat earlier, had been unable to deal with the rectangular hyperbola because his 'integration rule' broke down for $n=-1$. Mercator got around the problem by a change of axes so that he was handling $\frac{1}{1+a}$ rather than $\frac{1}{a}$, and then carried out long division to produce a power series for $\frac{1}{1+a}$. He was then able to 'integrate' term by term using Wallis's rule” (p. 95).

At the same time Newton independently developed similar infinite series, using a kinematic conception of curves as points with both geometric and algebraic relations. This allowed the number of curves accessible to analytic methods, which today we recognize as Taylor series, to be increased.

Like Mercator before him, Newton was inspired by the methods of Wallis, using them to calculate the $\mathrm{n}^{\text {th }}$ root of $x^{m}$, i.e. $x^{\frac{m}{n}}$ and $x^{\frac{-m}{n}}$, where $\mathrm{m}$ and $\mathrm{n}$ are integers, in order to determine what is known today as the binomial theorem. He used a long and complex method to derive the formula:

$$
(P+P Q)^{\frac{m}{n}}=P^{\frac{m}{n}}+\frac{m}{n} A Q+\frac{m-n}{2 n} B Q+\frac{m-2 n}{3 n} C Q+\cdots, \text { where } A=P^{\frac{m}{n}}, B=\frac{m}{n} A Q, \ldots
$$

where each of A, B, C, etc. represents the previous term in the expansion. Newton used his development of the theory as a computation tool to look at the expansion of specific functions. By substituting

$$
P=c^{2} \text { and } Q=\frac{x^{2}}{c^{2}}, \text { where } m=1 \text { and } n=2
$$


we get

$$
\left(c^{2}+x^{2}\right)^{\frac{1}{2}}=c+\frac{1}{2} c \frac{x^{2}}{c^{2}}+\frac{1(-1)}{2 \cdot 4} c\left(\frac{x^{2}}{c^{2}}\right)^{2}+\frac{1(-1)(-3)}{2 \cdot 4 \cdot 6} c\left(\frac{x^{2}}{c^{2}}\right)^{3}+\cdots=c+\frac{x^{2}}{2 c}-\frac{x^{4}}{8 c^{3}}+\frac{x^{6}}{16 c^{5}}-\cdots
$$

In particular, $\sqrt{1+x^{2}}=1+\frac{x^{2}}{2}-\frac{x^{4}}{8}+\frac{x^{6}}{16}-\frac{5 x^{8}}{128}+\cdots$ when $c=1$.

However, Newton never published this formula, and it was Wallis who formalized it in 1685, while attributing the discovery to Newton. It is how we commonly present the binomial theorem today:

$$
(1+x)^{m}=1+m x+\frac{m(m-1)}{2 !} x^{2}+\frac{m(m-1)(m-2)}{3 !} x^{3}+\cdots+\frac{m(m-1) \ldots(m-k+1)}{k !} x^{k}+\cdots
$$

A third era in the development of Taylor series occurred with the development of a power series for a more general class of function, which followed from what is now known as the Gregory-Newton interpolation method, which as noted by Stillwell (1989) rarely appears in calculus books today.

Taylor's formula was derived using the method of integration by parts developed by John Bernoulli and the method of finite differences used by Taylor, which gave a new context to the calculus. At that time Taylor's formula becomes a powerful tool for solving problems in mathematics and physics, in particular those involving approximation. As Taylor has not rigorously studied the remainder term in his formula, Maclaurin, Euler and Lagrange became interested in revisiting Taylor's work when developing their analytic methods in the eighteenth century. Lagrange broke a crisis of confidence in the formula using a numerical approach to the theory of series to determine approximate values of transcendental numbers. This showed the relevance of articulating different graphical, algebraic, and numerical registers as part of the analysis and confirmed the need for the inclusion of semantic and syntactic dimensions in the treatment of mathematical objects.

The mathematical rigor required revolved around the genesis of the concept of a limit, and it was d'Alembert who first suggested the need to incorporate them into the theory of calculus. This led to Cauchy, the father of the rigor, revisiting the various studies of Taylor's formula to incorporate answers to questions about its convergence. Similarly, Abel carefully studied the binomial theorem, while Weierstrass developed the fixed-point formula. One final stage of the historical development occurred when Poincaré studied the asymptotic behavior of Taylor series in 1886.

To illustrate the various historical eras described, we present Table 1, which includes the techniques used, along with their characteristics:

\begin{tabular}{|c|c|c|c|}
\hline Method & Period & Type of technique / Register & Dimension \\
\hline $\begin{array}{l}\text { Determination of the tangent and } \\
\text { initial elements of differential } \\
\text { calculus }\end{array}$ & $17^{\text {th }} \mathrm{c}$. & $\begin{array}{l}\text { Dynamic technique of Torricelli and Roberval / } \\
\text { Graphical } \\
\text { Dynamic technique of sub tangents by Fermat / } \\
\text { Graphical } \\
\text { Technique of extrema Fermat first } 2 \text { terms of the } \\
\text { current Taylor development / Graphical } \\
\text { Technique of geometric approximation applicable to } \\
\text { algebraic curves by Descartes / Algebraic and } \\
\text { graphical } \\
\text { Technique of Isaac Barrow / Geometric and } \\
\text { algebraic }\end{array}$ & $\begin{array}{l}\text { Semantic } \\
\text { Semantic } \\
\text { Mixed }\end{array}$ \\
\hline $\begin{array}{l}\text { The special case of developments in } \\
\text { infinite series }\end{array}$ & Since 1668 & $\begin{array}{l}\text { Geometric technique of Mercator / Graphical } \\
\text { Newtonian techniques/ Graphical and formal } \\
\text { Algebraic techniques of Leibniz / Graphical }\end{array}$ & $\begin{array}{l}\text { Mixed } \\
\text { Mixed }\end{array}$ \\
\hline $\begin{array}{l}\text { The series expansion of any } \\
\text { function and Taylor's formula }\end{array}$ & $18^{\text {th }} \mathrm{c}$. & $\begin{array}{l}\text { Algebraic techniques of Newton and Wallis / Formal } \\
\text { Analytic techniques to determine Taylor series / } \\
\text { Formal }\end{array}$ & $\begin{array}{l}\text { Syntactic } \\
\text { Mixed }\end{array}$ \\
\hline $\begin{array}{l}\text { The rigorous study of Taylor's } \\
\text { formula and the binomial formula } \\
\text { of Newton }\end{array}$ & 1826 & $\begin{array}{l}\text { Cauchy techniques to represent of Taylor's formula / } \\
\text { Formal } \\
\text { Algebraic and analytic technique of Abel / Formal }\end{array}$ & $\begin{array}{l}\text { Mixed } \\
\text { Syntactic }\end{array}$ \\
\hline Asymptotic expansion of Poincaré & 1886 & $\begin{array}{l}\text { Analytical techniques to represent Taylor series and } \\
\text { asymptotic developments / Formal }\end{array}$ & Syntactic \\
\hline
\end{tabular}

Table 1. Eras in the development of Taylor series 
During the formulation of the Taylor series of a function in the neighborhood of a real variable, mathematicians have used different techniques and mathematical frameworks involving algebra, analysis and geometry. Their methods articulated semantic and syntactic dimensions of connecting curves to their tangents, thus deriving equations in a manner that transitioned from the numerical register to the graphical, algebraic and analytic registers.

The geometric approach maintains an important place in the study of the first terms of Taylor's formula and in determining patterns in common infinite series expansions. However, we can see that in this initial period, mathematicians articulated semantic and syntactic dimensions in their graphical interpretation when considering techniques for developing analytical expressions.

Finally, we should also mention the concept of local comparisons of functions. Bourbaki (1994) confirms that its genesis is due to:

"... P. du Bois-Reymond, who first tackled systematically the problems of comparing functions in the neighborhood of a point, and, in very original works, recognized the "non-Archimedean" character of the scales of comparison, at the same time as he studied in a general way the integration and differentiation of the comparison relations, and drew from this a large number of interesting consequences. His proofs however lacked clarity and rigour, and it is to G.H. Hardy that the correct presentation of the results of du Bois-Reymond is due" (p. 202).

This historical survey has allowed us to identify the different eras in the development of Taylor series, which arose due to various problems in the fields of physics and mathematics.

\section{ANALYSIS OF CURRICULA, TEXTBOOKS AND COURSE HANDOUTS}

We looked at the introduction of Taylor series and Taylor polynomials in both the curriculum and the textbooks used in Tunisia and the United States, and more specifically those designated as preparatory classes in engineering. We believe it is an ideal place to study the teaching of Taylor series, since we (the teachers) are responsible for teaching the fundamentals of mathematics to provide a theoretical foundation appropriate for future engineers who will themselves have to model and articulate mathematics in the real world.

A study of the general recommendations by the nationally supervised Tunisian program (IPEIT, 2016) shows that the semantic and syntactic dimensions of Taylor series are generally included via different methods that encompass a variety of techniques (Table 2). However, there is a notable absence of key semantic dimensions. While the historical development of Taylor series revolved around different registers (analytical, algebraic, numerical, geometric and graphical) throughout its emergence, the program's recommendations are purely algebraic and analytic, with the graphical and numerical approaches being completely absent.

Table 2. Recommended content when teaching Taylor series in Tunisia

\begin{tabular}{|c|c|}
\hline Scientific content & Recommendations \\
\hline Taylor series of order $n$ of a function near a point. & $\begin{array}{l}\text { Students must learn how to determine, via simple examples, the } \\
\text { Taylor series of a composite function } f \text { o g. No general result is expected }\end{array}$ \\
\hline $\begin{array}{l}\text { Algebraic operations on Taylor series: sum, } \\
\text { product, division. }\end{array}$ & $\begin{array}{l}\text { from students. } \\
\text { The asymptotic expansions must be studied based on a few simple } \\
\text { examples. Any systematic study is excluded; in particular the theory of }\end{array}$ \\
\hline $\begin{array}{l}\text { Development of the Taylor-Young formula for } \\
\text { functions that are k-times differentiable. }\end{array}$ & $\begin{array}{l}\text { asymptotic analysis is not included. } \\
\text { It is convenient to give an example where } f \text { admits a Taylor expansion } \\
\text { of order } 2 \text { at a point without being twice differentiable at this point. }\end{array}$ \\
\hline
\end{tabular}

Four French language textbooks, two from Tunisia (Gatti, 2004; Karoui 2004) and two from France (AllanoChevalier \& Oudot, 2008; Monier, 2003), were also analyzed, along with three course handouts from Tunisian teachers at the Preparatory Institutes of Engineering Studies in Tunis and Nabeul to see if they followed the national guidelines in teaching Taylor series. We observed that they begin with a theoretical presentation of the object, in a purely syntactical form, using definitions, theorems, and properties in an analytical register. They then pass directly to a purely analytical discussion using limits, along with local approximations of the function (either in the neighborhood of a point or in the neighborhood of infinity), using Taylor series which utilize articulate both semantic and syntactic dimensions via analytic, algebraic and geometric techniques. Instead of using a geometric figure to motivate the interest in Taylor series as models for approximating the local behavior of functions (see Figure 2), the course materials almost entirely omitted this essential feature. 


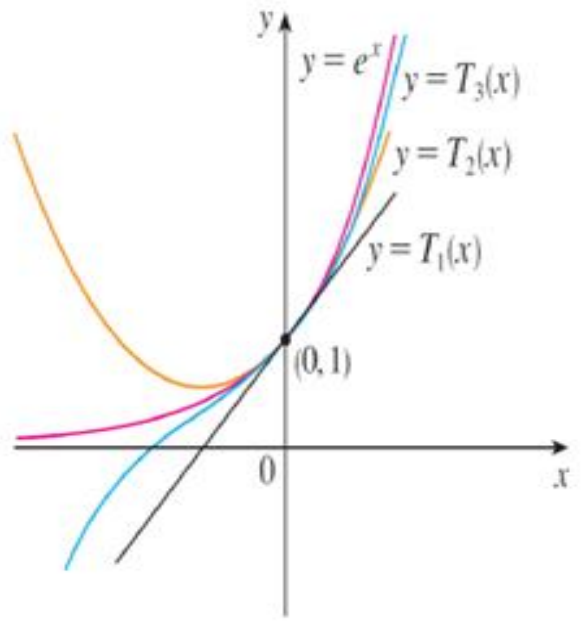

Figure 2. Taylor polynomials for the curve $y=e^{x}$

In the United States there is no national curriculum at the post-secondary level. However, if we look at the guidelines for teaching Taylor series to prepare high school students for the Advanced Placement exam (College Board, 2016), we see that the enduring knowledge expected of students is that they will recognize that a function can be represented by an associated power series over its interval of convergence. It is also advised that students graph Taylor polynomials using a calculator to better understand the interval of convergence. If we look at the specific learning objectives and associated recommendations (Table 3), the concentration is again on algebraic and analytic techniques, with the graphic and numerical registers marginalized.

Table 3. Recommended content when teaching Taylor series in Tunisia

\begin{tabular}{ll}
\hline Scientific content & Recommendations \\
\hline Taylor series of order $n$ of a function near a point. & $\begin{array}{l}\text { Students must learn how to determine, via simple examples, the } \\
\text { Taylor series of a composite function fog. No general result is expected } \\
\text { from students. }\end{array}$ \\
$\begin{array}{ll}\text { Algebraic operations on Taylor series: sum, } \\
\text { product, division. }\end{array}$ & $\begin{array}{l}\text { The asymptotic expansions must be studied based on a few simple } \\
\text { examples. Any systematic study is excluded; in particular the theory of }\end{array}$ \\
$\begin{array}{ll}\text { Development of the Taylor-Young formula for } \\
\text { functions that are k-times differentiable. }\end{array}$ & $\begin{array}{l}\text { It is convenient to give an example where } f \text { admits a Taylor expansion } \\
\text { of order } 2 \text { at a point without being twice differentiable at this point. }\end{array}$ \\
\hline
\end{tabular}

Four American handouts on Taylor series were also analyzed, all from large state universities, which distilled the topic into the essential knowledge that students should have. In each case the graphical and numerical registers were omitted, with the focus being on algebraic manipulation and connections to the symbolic register. The only exception was that in one instance the Maclaurin series for $e^{x}$ was used to write out the first few terms for $e$, though even in this case no numerical value was stated.

Finally, we looked at the textbooks by Stewart (2016) and Thomas et al. (2018), which are commonly used in calculus classes throughout the United States. Here we found a much greater use of the graphic and numerical registers to display the polynomial approximations to functions, similar to that in Figure 2, along with a discussion of how changing the center of the Taylor series can be beneficial when making a local approximation, and how the rate of convergence can change for different values of the variable depending on the distance from the center. Examples were given, along with exercises that encouraged students to use a graphing calculator to compare the function with its Taylor polynomial. 


\section{CONCLUSION}

This study concentrates on one aspect of mathematical education, namely the semiotics of instruction, and argues that a different emphasis in teaching practices could be used to facilitate learning when introducing Taylor series and linear approximations into the curriculum.

The comparative analysis of the documents described shows the difference in both Tunisia and the United States between the historical evolution of the applications of Taylor series using the various techniques described and the teaching techniques that are recommended now. In particular, the historical development revolved around different semiotic registers (analytic, algebraic, numerical, geometric, and graphic), whereas the approach used in contemporary classrooms often omits important aspects of the evolution that enabled mathematicians to advance their research in the development of a new object that subsequently became a fundamental tool in mathematical approximations used in several disciplines.

On the institutional side, the relevance of the relationship between the semantic and syntactic point of view needs to be taken into account by university educators. This causes us to consider important aspects of the theory which are not currently reflected in curricula and course handouts. The numerical and graphical approaches are needed to show the relevance of Taylor series in the engineering sciences. In particular, the graphical register should be included so that students can reach a better conceptualization of the notion of approximation and asymptotic behavior. The benefit of doing this was demonstrated to a statistically significant level by McGee and Martinez-Planell (2014), who stated (with regard to multivariable integrals) that "the inclusion of the added registers appears to improve students' ability to solve general integral problems" (p. 901).

We are not suggesting a more informal way of teaching the concepts, but rather that it would be more appropriate to dwell initially on graphical and numerical aspects before beginning the formal analytic and algebraic manipulations. This will especially aid the mathematical training of future engineers, who are required not only to understand the theory, but also to use it as a practical tool when needed. It is our intention to conduct further experiments that will explore this topic in greater detail, with a focus on undergraduate students planning to become engineers.

\section{Disclosure statement}

No potential conflict of interest was reported by the authors.

\section{Notes on contributors}

Rahim Kouki - Département de Mathématique et Informatique, Université de Tunis El Manar, Tunis 2092, Tunisia.

Barry J. Griffiths - Department of Mathematics, University of Central Florida, Orlando, FL 32816-1364, USA.

\section{REFERENCES}

Allano-Chevalier, M., \& Oudot, X. (2008). Maths MPSI 1e année. Paris, France: Hachette.

Artigue, M. (2004). Le défi de la transition secondaire/supérieur : Que peuvent nous apporter les recherches didactiques et les innovations développées dans ce domaine? First Franco-Canadian Mathematics Conference, July 2004, Toulouse.

Bloch I., \& Gibel P. (2011). Un modèle d'analyse des raisonnements dans les situations didactiques : Étude des niveaux de preuves dans une situation d'enseignement de la notion de limite. Recherche en Didactique des Mathématiques, 31(2), 191-228.

Bourbaki, N. (1994). Elements of the history of mathematics. Berlin, Germany: Springer. https://doi.org/10.1007/978-3-642-61693-8

Chevallard, Y. (1992). Concepts fondamentaux de la didactique : Perspectives apportées par une approche anthropologique. Recherches en Didactique des Mathématiques, 12(1), 73-112.

College Board. (2016). AP calculus AB and AP calculus BC course and exam description. Retrieved from https://apcentral.collegeboard.org/pdf/ap-calculus-ab-and-bc-course-and-exam-description.pdf 
Dahan-Dalmédico, A., \& Peiffer, J. (2010). History of Mathematics: Highways and Byways. Washington, DC: The Mathematical Association of America.

Durand-Guerrier, V. (2008). Truth versus validity in mathematical proof. ZDM-The International Journal on Mathematics Education, 40(3), 373-384. https://doi.org/10.1007/s11858-008-0098-8

Durand-Guerrier, V., \& Arsac, G. (2005). An epistemological and didactic study of a specific calculus reasoning rule. Educational Studies in Mathematics, 60(2), 149-172. https://doi.org/10.1007/s10649-005-5614-y

Gatti, M. (2004). Analyse II: Cours et 260 exercices corrigés. Tunis, Tunisia: Omega.

Institut préparatoire aux études d'ingénieurs de Tunis. (2016). Classes préparatoires MP: Programme de mathématiques première année. Retrieved from http://www.ipeit.rnu.tn/sites/default/files/Prog Maths MP 1ère année.pdf

Karoui, A. (2004). Analyse : Cours de mathématiques de première année. Tunis, Tunisia: Centre de Publication Universitaire.

Kouki, R. (2018). L'articulation des dimensions syntaxique et sémantique en algèbre du secondaire. Recherches en Didactique des Mathématiques, 38(1), 43-78.

Kouki, R., Belhaj Amor, F., \& Hachaïchi, Y. (2016). Comparaison entre l'évolution historique ayant mené aux développements limités et leur pratique d'enseignement au début de l'université : Entre syntaxe et sémantique. In E. Nardi, C. Winslow \& T. Hausberger (Eds.), Proceedings of the 1st Conference of the International Network for Didactic Research in University Mathematics (pp. 123-132). Montpellier: INDRUM.

McGee, D. \& Martinez-Planell, R. (2014). A study of semiotic registers in the development of the definite integral of functions of two and three variables. International Journal of Science and Mathematics Education, 12(4), 883-916. https://doi.org/10.1007/s10763-013-9437-5

Monier, J.-M. (2003). Analyse MPSI : Cours et 1000 exercices corrigés. Paris, France: Dunod.

Stedall, J. (2008). Mathematics emerging: A sourcebook 1540-1900. Oxford, UK: Oxford University Press.

Stewart, J. (2016). Calculus. Boston, MA: Cengage.

Stillwell, J. (1989). Mathematics and its history. New York, NY: Springer. https://doi.org/10.1007/978-1-48990007-4

Thomas, G., Haas, J., Heil, C., \& Weir, M. (2018). Thomas'calculus. Boston, MA: Pearson. 